\title{
Operative timing is associated with increased morbidity and mortality in patients undergoing emergency general surgery: a multisite study of emergency general services in a single academic network
}

\author{
Michael T. Meschino, MD \\ Andrew E. Giles, MD, MPH \\ Timothy J. Rice, MD \\ Maisa Saddik, MSc \\ Aristithes G. Doumouras, MD, MPH \\ Rahima Nenshi, MD, MSc \\ Laura Allen, MSc \\ Kelly Vogt, MD, MSc \\ Paul T. Engels, MD
}

Presented at the Canadian Surgery Forum, Sept. 5-7, 2019, Montréal, Que.

Accepted Nov. 5, 2019

\section{Correspondence to: \\ P. Engels \\ Hamilton General Hospital \\ 6 North Wing, Rm 617 \\ 237 Barton St E \\ Hamilton ON L8L 2X2 \\ engelsp@mcmaster.ca}

DOI: 10.1503/cjs.012919
Background: Despite the widespread implementation of the acute care surgery (ACS) model, limited access to operating room time represents a barrier to the optimal delivery of emergency general surgery (EGS) care. The objective of this study was to describe the effect of operative timing on outcomes in EGS in a network of teaching hospitals.

Methods: We conducted a retrospective review of EGS operations performed at 3 teaching hospitals in a single academic network. Time of operation was categorized as daytime ( $8 \mathrm{am}$ to $5 \mathrm{pm})$, after hours $(5 \mathrm{pm}$ to $11 \mathrm{pm})$ or overnight (11 pm to $8 \mathrm{am})$. Time to operation was calculated as the interval from admission to operative start time and categorized as less than 24 hours, 24-72 hours and greater than 72 hours.

Results: After we excluded nonindex cases, trauma cases and cases occurring more than 5 days after admission, 1505 EGS cases were included. We found that $39.0 \%$ of operations were performed in the daytime, $46.3 \%$ after hours and $14.8 \%$ overnight. In terms of time to operation, $52.3 \%$ of operations were performed within 24 hours of admission, $33.4 \%$ in $24-72$ hours and $14.3 \%$ in more than 72 hours. The overall complication rate was $20.6 \%$ (310 patients) and the overall mortality rate was $3.8 \%$ (57 patients). After multivariable analysis, time to operation more than 72 hours after admission was independently associated with increased odds of morbidity (odds ratio [OR] 1.64, 95\% confidence interval $[\mathrm{CI}]$ 1.09-2.47), while overnight operating was associated with increased odds of death (OR 3.15, 95\% CI 1.29-7.70).

Conclusion: Increasing time from admission to operation and overnight operating were associated with greater morbidity and mortality, respectively, for EGS patients. Strategies to provide timely access to the operating room should be considered to optimize care in an ACS model.

Contexte : Même si le modèle de chirurgie en soins actifs (CSA) est largement répandu, l'accès limité aux blocs opératoires représente un obstacle à la chirurgie générale chez les patients des services d'urgence (CGSU). L'objectif de cette étude était de décrire l'effet du moment de l'intervention sur l'issue des CGSU dans un réseau d'hôpitaux universitaires.

Méthodes : Nous avons procédé à une revue des CGSU effectuées dans 3 hôpitaux d'enseignement d'un réseau universitaire. Le moment opératoire était catégorisé selon que les interventions étaient effectuées le jour $(8 \mathrm{~h} 00$ à $17 \mathrm{~h} 00)$, le soir $(17 \mathrm{~h} 00$ à $23 \mathrm{~h} 00)$ ou la nuit $(23 \mathrm{~h} 00$ à 8 h 00$)$. Le délai opératoire représentait l'intervalle entre l'admission et le début de l'intervention et était réparti selon les catégories suivantes : moins de 24 heures, de 24 à 72 heures et plus de 72 heures.

Résultats : Après exclusion des cas non index, des cas de traumatologie et des cas survenus plus de 5 jours après l'admission, 1505 CGSU ont été incluses. Nous avons constaté que 39,0\% des interventions avaient été effectuées le jour, 46,3\% le soir et 14,8\% la nuit. Pour ce qui est du délai opératoire, $52,3 \%$ des interventions ont été effectuées dans les 24 heures suivant l'admission, 33,4\% dans les 24 à 72 heures et $14,3 \%$ plus de 72 heures après l'admission. Le taux global de complications a été de 20,6\% (310 patients) et le taux de mortalité global a été de 3,8\% (57 patients). Après analyse multivariée, le délai opératoire de plus de 72 heures suivant l'admission a été associé de manière indépendante à un risque accru de morbidité (rapport ces cotes [RC] 1,64, intervalle de confiance [IC]) de $95 \% 1,09$ à 2,47), tandis que les interventions effectuées la nuit ont été associées à un risque de décès plus élevé (RC 3,15, IC de $95 \%$ 1,29 à 7,70).

Conclusion : L'augmentation du délai entre l'admission et l'intervention et les interventions de nuit ont été associées à une morbidité et une mortalité plus élevées, respectivement, chez les patients soumis à des CGSU. Des stratégies visant à offrir un accès rapide aux blocs opératoires sont à envisager pour optimiser le modèle de CSA. 
T he advent of the acute care surgery (ACS) model brought the promise of improved outcomes for the emergency general surgery (EGS) patient population. Over the last decade, extensive research has highlighted the benefits of the ACS model for patient- and hospital-specific outcomes. ${ }^{1-7}$

Despite the widespread implementation of the ACS model in Canada, lack of access to the operating room is a common issue facing many EGS services across the country. A recent national review of EGS services in Canada found that less than half of hospitals that employ the ACS model have dedicated access to the OR for EGS patients during the day. Not surprisingly, nearly $50 \%$ of all EGS procedures in Canada continue to take place after hours or overnight, between $5 \mathrm{pm}$ and $8 \mathrm{am} .^{8}$

The impacts of after-hours operating and delay to operative intervention have been described in the literature. For hip fractures, for example, studies have shown that afterhours operating and operative delay lead to increased morbidity and mortality. ${ }^{9,10}$ Furthermore, implementation of dedicated daytime operating room resources to address hip fractures has resulted in significant improvements in disease-specific outcomes, in part by limiting operative delay and overnight operating. ${ }^{11,12}$

Similar research in EGS is less conclusive. Multiple studies have examined the impact of after-hours operating on appendectomy and cholecystectomy outcomes, with mixed results. ${ }^{13-18}$ Delay to operative intervention has been difficult to study because of the diversity of disease processes, severity of presentation and variable comorbidities in EGS patients.

Despite the implementation of ACS models in our academic network, access to the OR represents a substantial barrier to timeliness of care for our EGS patients. The purpose of this study was to describe the impact of operative timing on EGS outcomes in our network. Our primary objectives were to determine the association, if any, of time elapsed from admission to operation, with morbidity and mortality of EGS patients and to determine the association, if any, of timing of operation (day, after hours, overnight) with morbidity and mortality of EGS patients. Secondarily, we sought to characterize the timing of operation of EGS patients in our centre and to obtain detailed information on disease distribution.

\section{Methods}

\section{Study design and data collection}

This study was a retrospective review of all EGS operative cases performed throughout the 3 adult teaching hospitals in our academic health sciences network (Hamilton Health Sciences and St. Joseph's Healthcare Hamilton). Data were collected on all EGS cases performed from Jan. 1 to Dec. 31, 2014. Cases were identified through each hospital's operating room administrative data set. Data were derived through this data set and electronic chart review. Ethics approval was obtained from the Hamilton Integrated Research Ethics Board.

\section{Context}

Each of the 3 sites used a different EGS model of care: an ACS model with allocated daytime operating room access, an ACS model with no allocated daytime operating room access, or general surgeon on call (24 h) with no ACS team and no allocated daytime operating room access. In addition, each hospital serviced unique patient populations (Table 1).

\section{Inclusion and exclusion criteria}

All nonelective EGS operations performed on adult patients by the ACS service or on-call surgeon were reviewed. Nonemergent and elective semiurgent operations were excluded. In addition, we excluded all secondary cases (e.g., repeat laparotomies) and cases that were not categorized as general surgery cases. Trauma cases were excluded because the physiology and management of patients with traumatic injuries treated operatively were not comparable to those of EGS patients.

Cases in which the patient underwent an operation more than 5 days after admission were excluded. In choosing a timing cut-off, we considered that most EGS patients will require surgery within hours to days, but several situations would alter this assumption. These would include conditions requiring preoperative investigation or procedures (choledocholithiasis) or initial nonoperative management (small bowel obstruction), or situations in which the patient requires preoperative medical optimization. Most of these situations could occur within 5 days. Expanding our cut-off further would probably capture procedures performed on patients admitted for other reasons who subsequently developed an emergency surgical condition. Such patients would have different baseline characteristics than other patients, and the time from admission to operation would not be as representative as a potential marker of delayed operative management.

\section{Sensitivity analyses}

We tested the above assumptions using 3 sensitivity analyses. The first 2 altered time to operation cut-offs. First, we included all patients to test whether limiting our analysis to patients having surgery in the few days after admission produced results that differed dramatically from those produced when we included patients with prolonged admission. Second, we restricted the analysis to patients who had surgery within 10 days of admission. A third sensitivity analysis maintained the 5 day cut-off but excluded disease categories that we anticipated would be associated with a preoperative delay (choledocholithiasis, small bowel obstruction). 


\begin{tabular}{|c|c|c|c|c|}
\hline \multirow[b]{2}{*}{ Characteristic } & \multicolumn{4}{|c|}{ No. $(\%)$ of patients* } \\
\hline & $\begin{array}{c}\text { Overall } \\
n=1505\end{array}$ & $\begin{array}{c}\text { Site } 1 \dagger \\
\text { (ACS, day OR) } \\
n=548\end{array}$ & $\begin{array}{c}\text { Site } 2 \ddagger \\
\text { (ACS, no day OR) } \\
n=593\end{array}$ & $\begin{array}{c}\text { Site } 3 \S \\
\text { (No ACS, no day OR) } \\
n=364\end{array}$ \\
\hline Age, yr, mean $\pm S D$ & $51.9 \pm 19.35$ & $54.1 \pm 19.28$ & $50.3 \pm 19.70$ & $51.3 \pm 18.68$ \\
\hline Female sex & $819(54.4)$ & $303(55.3)$ & $332(56.0)$ & $184(50.6)$ \\
\hline \multicolumn{5}{|l|}{ Disease type } \\
\hline Cholecystitis & $364(24.4)$ & $132(24.5)$ & $148(25.0)$ & $84(23.3)$ \\
\hline Choledocholithiasis & $63(4.2)$ & $19(3.5)$ & $34(5.8)$ & $10(2.8)$ \\
\hline Appendiceal disease & 355 (23.6) & 107 (19.5) & $152(25.6)$ & $96(26.4)$ \\
\hline Large bowel disease & 189 (12.6) & $80(14.6)$ & $68(11.5)$ & $41(11.3)$ \\
\hline Small bowel disease & 164 (10.9) & 79 (14.4) & $54(9.1)$ & $31(8.5)$ \\
\hline Hernia & $129(8.6)$ & $38(6.9)$ & $60(10.1)$ & $31(8.5)$ \\
\hline Perianal disease & $87(5.8)$ & $42(7.7)$ & $15(2.5)$ & $30(8.2)$ \\
\hline Gastric disease & $46(3.1)$ & $12(2.2)$ & $25(4.2)$ & $9(2.5)$ \\
\hline Breast disease & $12(0.8)$ & $2(0.4)$ & $3(0.5)$ & $7(1.9)$ \\
\hline Hepatopancreatobiliary disease & $1(0.1)$ & $1(0.2)$ & $0(0.0)$ & $0(0.0)$ \\
\hline Other & $80(5.3)$ & $27(4.9)$ & $32(5.4)$ & $21(5.8)$ \\
\hline \multicolumn{5}{|l|}{ Time to operation } \\
\hline$<24 \mathrm{~h}$ & $761(52.3)$ & $297(54.3)$ & $248(44.4)$ & $216(61.5)$ \\
\hline $24-72 \mathrm{~h}$ & 487 (33.4) & $174(31.8)$ & $225(40.3)$ & $88(25.1)$ \\
\hline $72-120 \mathrm{~h}$ & $208(14.3)$ & 76 (13.9) & $85(15.2)$ & $47(13.4)$ \\
\hline \multicolumn{5}{|l|}{ Time of operation } \\
\hline Daytime & $586(39.0)$ & $254(46.5)$ & $168(28.3)$ & $164(45.2)$ \\
\hline After hours & $695(46.3)$ & 209 (38.3) & $328(55.3)$ & $158(43.5)$ \\
\hline Overnight & $221(14.7)$ & $83(15.2)$ & $97(16.4)$ & $41(11.3)$ \\
\hline \multicolumn{5}{|l|}{ Adverse outcomes } \\
\hline Complications & $310(20.6)$ & 109 (19.9) & 118 (19.9) & 83 (22.8) \\
\hline In-hospital mortality & $57(3.8)$ & $25(4.6)$ & $13(2.2)$ & $19(5.2)$ \\
\hline \multicolumn{5}{|c|}{$\begin{array}{l}\text { ACS = acute care surgery; } \mathrm{OR}=\text { operating room; } \mathrm{SD}=\text { standard deviation. } \\
\text { *Unless indicated otherwise. } \\
\text { †ACS initiated in 2011. Surgical specialties: oncology, hepatobiliary, colorectal, urology, arthroplasty, plastic. } \\
\text { ¥ACS initiated in 2013. Surgical specialties: bariatric, thoracic, otolaryngology, obstetrics, urology. } \\
\text { §No ACS. Surgical specialties: trauma, cardiac, neurosurgery, spine, vascular, orthopedics, plastics/burns. }\end{array}$} \\
\hline
\end{tabular}

\section{Variables}

Outcome variables included complications, defined as any postoperative adverse event occurring during hospital admission, and in-hospital mortality. Explanatory variables included the demographic characteristics age and sex. Time to operation was calculated by subtracting the date and time of the start of the operation from the date and time of admission. This was further categorized as less than 24 hours, 24-72 hours and more than 72 hours. Time of operation was categorized as daytime (Monday to Friday, 8 am to $5 \mathrm{pm}$ ), after hours (Monday to Friday, $5 \mathrm{pm}$ to $11 \mathrm{pm}$; Saturday and Sunday, 8 am to $11 \mathrm{pm})$ or overnight (11 pm to $7 \mathrm{am})$. Other variables collected were pre- and postoperative diagnosis and operative intervention performed.

\section{Statistical analysis}

Summary and descriptive statistics were tabulated and reported as means with standard deviations for normally distributed data. Univariable analysis was conducted comparing categorical variables using the $\chi^{2}$ test or Fisher exact test. Generalized linear mixed-effects logistic regression was used to determine independent effects of preoperative factors on complications and mortality. The dependent variables were postoperative complications and mortality. Independent variables were age (by deciles), sex, disease type, time to operation (by category) and timing of operation (daytime, after hours, overnight). Certain variables were excluded from regression analysis because there were too few cases (i.e., hepatopancreatobiliary operations) or no events (i.e., no deaths among patients who underwent breast operations) or because of heterogeneity (i.e., the "other" operation category). Hospital site was used as a random effects variable to account for the potential clustering effect by hospital. The variables were selected for forced inclusion; no stepwise selection process was used. Adjusted odds ratios (ORs) with 95\% confidence intervals (CIs) are reported. Analysis was performed using $\mathrm{R}$ version 3.5.3 ( $\mathrm{R}$ Foundation). 


\section{RESULts}

\section{Patient characteristics}

In total, 1874 nonelective EGS operative cases were identified. After we excluded 139 nonindex cases (e.g., repeat laparotomy, abdominal wall closure), 14 trauma cases, and 216 cases delayed more than 5 days after admission, 1505 cases were included in the analysis (Fig. 1). The mean age of the patient population was 53 years. Fifty-four percent of patients were women $(n=819)$. Appendectomy and cholecystectomy represented just over $50 \%$ of cases. Overall, the in-hospital complication and mortality rates were

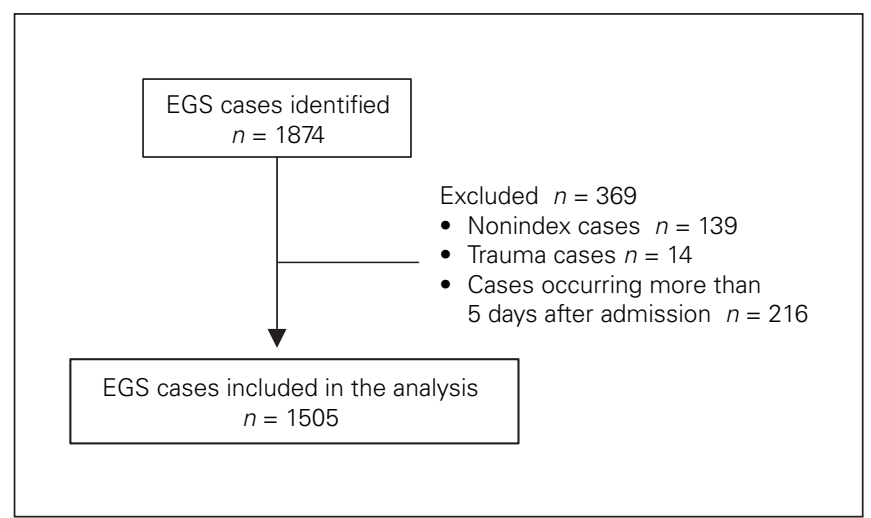

Fig. 1. Patient flowchart. EGS = emergency general surgery.
$20.6 \%(n=310)$ and 3.8\% $(n=57)$, respectively (Table 1$)$. Surgical site infection (SSI) was the most common complication $(5.1 \%, n=77)$, followed by postoperative ileus (3.6\%, $n=54)$ and pneumonia $(2.8 \%, n=42)$ (Fig. 2).

\section{Time to operation}

In the majority of cases (52.3\%), operations occurred within 24 hours of admission; operations occurred within 24-72 hours of admission and more than 72 hours after admission in $33.4 \%$ and $14.3 \%$ of cases, respectively (Table 1). The rate of in-hospital complications was greatest among cases with time to operation greater than 72 hours $(17.1 \%, 22.2 \%$ and $32.7 \%$ for cases performed in less than $24 \mathrm{~h}$, within $24-72 \mathrm{~h}$ and more than $72 \mathrm{~h}$ after admission, respectively; $p<0.001$; Table 2). There was no difference in mortality. After multivariable analysis, time to operation greater than 72 hours was independently associated with an increased risk of morbidity (OR 1.64, 95\% CI 1.09-2.47, $p=0.02$ ) (Table 3, Fig. 3).

\section{Time of operation}

More operations were performed after hours $(46.3 \%$ of cases, $n=695)$ than during the daytime $(39.0 \%, n=586)$ and overnight $(14.8 \%, n=221)$. Overall, on univariate

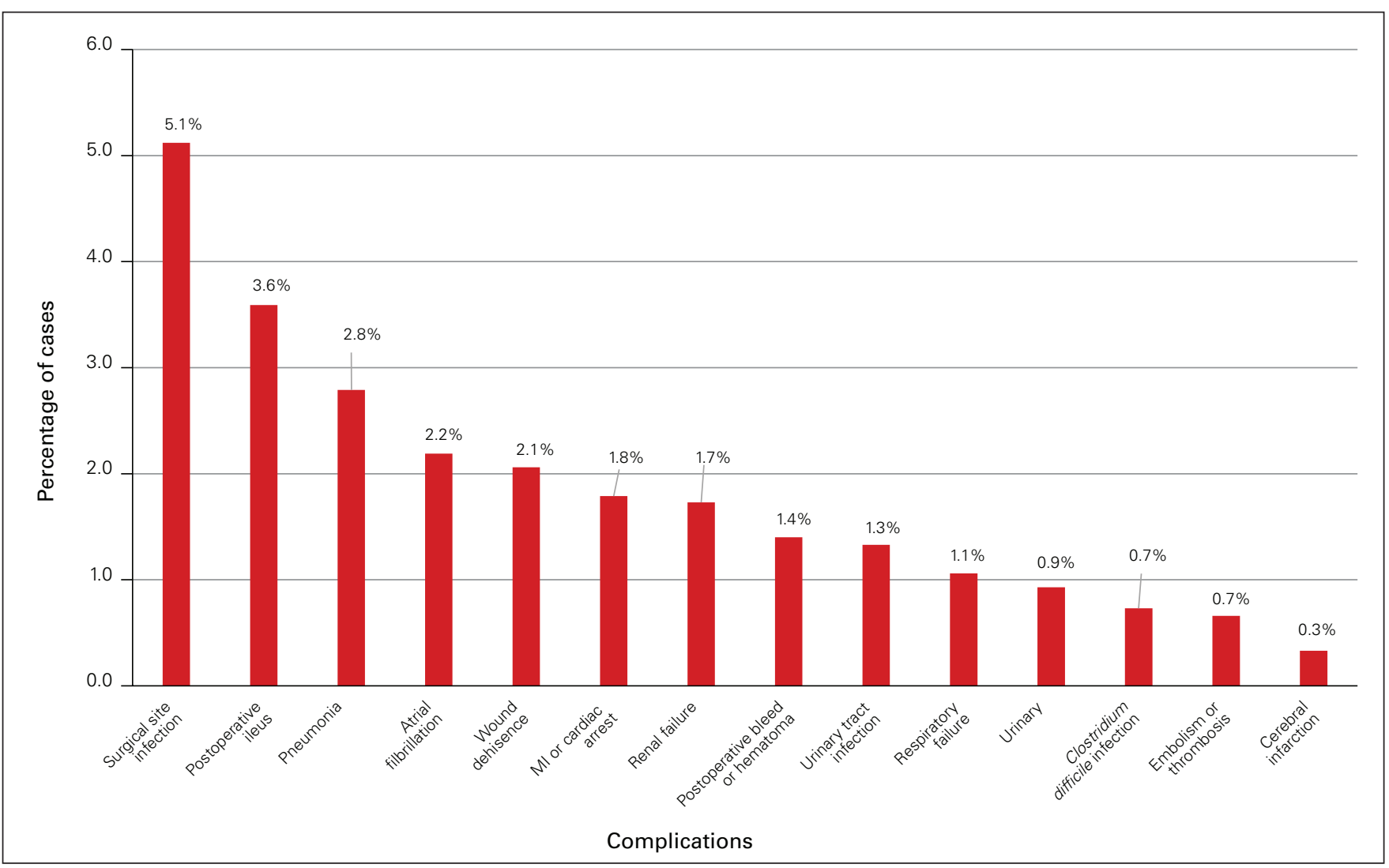

Fig. 2. In-hospital complications. MI = myocardial infarction. 
analysis there was no difference in the rate of complications or mortality (Table 2). However, regression analysis revealed that overnight operations were independently associated with an increased risk of death compared with daytime operations (OR 3.15, 95\% CI 1.29-7.70, $p=0.01$ ) (Table 3, Fig. 3).

\section{Multivariable analysis}

In addition to the above findings, morbidity was independently associated with pathology type. With ref-

\begin{tabular}{|c|c|c|c|c|}
\hline & \multicolumn{2}{|c|}{ Complications } & \multicolumn{2}{|c|}{ Mortality } \\
\hline & $\begin{array}{c}\text { No. }(\%) \\
\text { of patients }\end{array}$ & $p$ value & $\begin{array}{c}\text { No. (\%) } \\
\text { of patients }\end{array}$ & $p$ value \\
\hline \multicolumn{5}{|l|}{$\begin{array}{l}\text { Time to } \\
\text { operation }\end{array}$} \\
\hline$<24 \mathrm{~h}$ & $130(17.1)$ & $<0.001$ & $24(3.2)$ & 0.12 \\
\hline $24-72 \mathrm{~h}$ & $108(22.2)$ & & 19 (3.9) & \\
\hline$>72 \mathrm{~h}$ & $68(33.0)$ & & $13(6.2)$ & \\
\hline \multicolumn{5}{|l|}{$\begin{array}{l}\text { Time of } \\
\text { operation }\end{array}$} \\
\hline Daytime & 115 (19.6) & 0.39 & $15(2.6)$ & 0.07 \\
\hline After hours & $142(20.4)$ & & 27 (3.9) & \\
\hline Overnight & $53(24.0)$ & & $13(5.9)$ & \\
\hline
\end{tabular}

erence to cholecystitis, the cases relating to small bowel, large bowel, gastric disease and hernias were associated with an increased risk of complications (Table 3). With the exception of hernia cases, the same trend held true for mortality.

\section{Sensitivity analyses}

Details of the sensitivity analysis can be found in Appendix 1, Supplemental Tables S1 and S2 (available at canjsurg.ca/012919-a1). When we expanded the analysis to include patients who had surgery within 10 days of admission, and when we subsequently included all patients, there was a marginally increased risk of complications if the operation was performed after 72 hours (OR 1.83, 95\% CI 1.28-2.62; OR 2.52, 1.83-3.46). Otherwise there was no major difference from our final model.

With regard to mortality, expansion of the inclusion criteria did not alter the main finding that overnight operations are associated with an increased risk of mortality compared with daytime operations. There was an association with timing greater than 72 hours after admission that occurred only in the model including all patients.

When we restricted the analysis to patients expected to be booked for an operation without preoperative delay, no substantive changes were seen in either the complication or mortality models (Appendix 1, Supplemental Tables S1 and S2).
Table 3. Regression analyses for complications and mortality

\begin{tabular}{|c|c|c|c|c|}
\hline \multirow[b]{2}{*}{ Factor } & \multicolumn{2}{|c|}{ Complications } & \multicolumn{2}{|l|}{ Mortality } \\
\hline & OR $(95 \% \mathrm{Cl})$ & $p$ value & OR $(95 \% \mathrm{Cl})$ & $p$ value \\
\hline Age, deciles & $1.38(1.27-1.50)$ & $<0.001$ & $1.59(1.30-1.95)$ & $<0.001$ \\
\hline Male sex (Ref female) & $1.26(0.94-1.69)$ & 0.12 & $0.95(0.50-1.81)$ & 0.88 \\
\hline \multicolumn{5}{|l|}{ Disease type } \\
\hline Cholecystitis & Ref & - & Ref & - \\
\hline Choledocholithiasis & $1.06(0.46-2.45)$ & 0.89 & $1.93(0.19-19.43)$ & 0.58 \\
\hline Appendicitis & $1.24(0.75-2.02)$ & 0.40 & $1.24(0.24-6.32)$ & 0.80 \\
\hline $\begin{array}{l}\text { Large bowel } \\
\text { disease }\end{array}$ & $4.10(2.59-6.49)$ & $<0.001$ & $6.70(1.87-24.10)$ & $<0.001$ \\
\hline $\begin{array}{l}\text { Small bowel } \\
\text { disease }\end{array}$ & $4.93(3.05-7.95)$ & $<0.001$ & $7.47(2.03-27.50)$ & $<0.001$ \\
\hline Hernia & $1.87(1.08-3.23)$ & 0.03 & $2.00(0.39-10.25)$ & 0.41 \\
\hline Perianal disease & $0.65(0.26-1.62)$ & 0.35 & $3.37(0.53-21.57)$ & 0.20 \\
\hline Gastric disease & $5.22(2.56-10.65)$ & $<0.001$ & $18.50(4.25-80.45)$ & $<0.001$ \\
\hline Breast disease* & $1.23(0.14-10.76)$ & 0.85 & Ref & - \\
\hline \multicolumn{5}{|l|}{ Time to operation } \\
\hline$<24 \mathrm{~h}$ & Ref & - & Ref & - \\
\hline $24-48 \mathrm{~h}$ & $1.24(0.88-1.73)$ & 0.22 & $0.83(0.38-1.80)$ & 0.64 \\
\hline$>72 \mathrm{~h}$ & $1.64(1.09-2.47)$ & 0.02 & $1.21(0.53-2.76)$ & 0.66 \\
\hline \multicolumn{5}{|l|}{ Time of operation } \\
\hline Daytime & Ref & - & Ref & - \\
\hline After hours & $1.03(0.74-1.43)$ & 0.86 & $1.53(0.71-3.29)$ & 0.27 \\
\hline Overnight & $1.32(0.86-2.05)$ & 0.21 & $3.15(1.29-7.70)$ & 0.01 \\
\hline
\end{tabular}

\section{Cholecystitis}

In 364 cases $(24.4 \%)$, the operation was performed to treat cholecystitis; $98.0 \%$ of these operations were completed laparoscopically. Time to operation was as follows: $45.5 \%$ within 24 hours of admission, $39.8 \%$ within $24-72$ hours of admission and $14.8 \%$ more than 72 hours after admission (Table 4). A majority of cases occurred during the daytime $(42.3 \%)$, while $44.2 \%$ took place after hours and $13.4 \%$ overnight.

The incidence of complications rose with increasing time to operation: patients experienced complications in $6.2 \%$ cases in which the operation was performed within 24 hours, in $14.3 \%$ of cases in which the operation was performed between 24 and 72 hours and in $19.2 \%$ of cases in which the operation was performed more than 72 hours after admission $(p=0.01)$. There was no difference in complication rate based on time of day $(p=0.89)$. The mortality rate was low for biliary disease, and no significant difference was found for time to operation or operative timing. 


\section{Appendicitis}

Appendectomies accounted for 355 cases (23.6\%), of which $96.9 \%$ were completed laparoscopically. Time to operation was as follows: $69.9 \%$ of operations were performed within 24 hours, $22.6 \%$ within $24-72$ hours and $7.4 \%$ more than 72 hours after admission (Table 4). In almost half of cases (49.3\%) the operation was performed after hours (49.3\%), and in the remainder of the cases the operataion was performed during the daytime (33.8\%) or overnight (16.9\%). There was no difference in complication or mortality rates based on operative timing or time to operation.

\section{Discussion}

The ACS model has been seen as a solution to many challenges in EGS. ${ }^{1-7}$ Patients may anticipate more coordinated care, a shorter wait time for an operation and a shorter

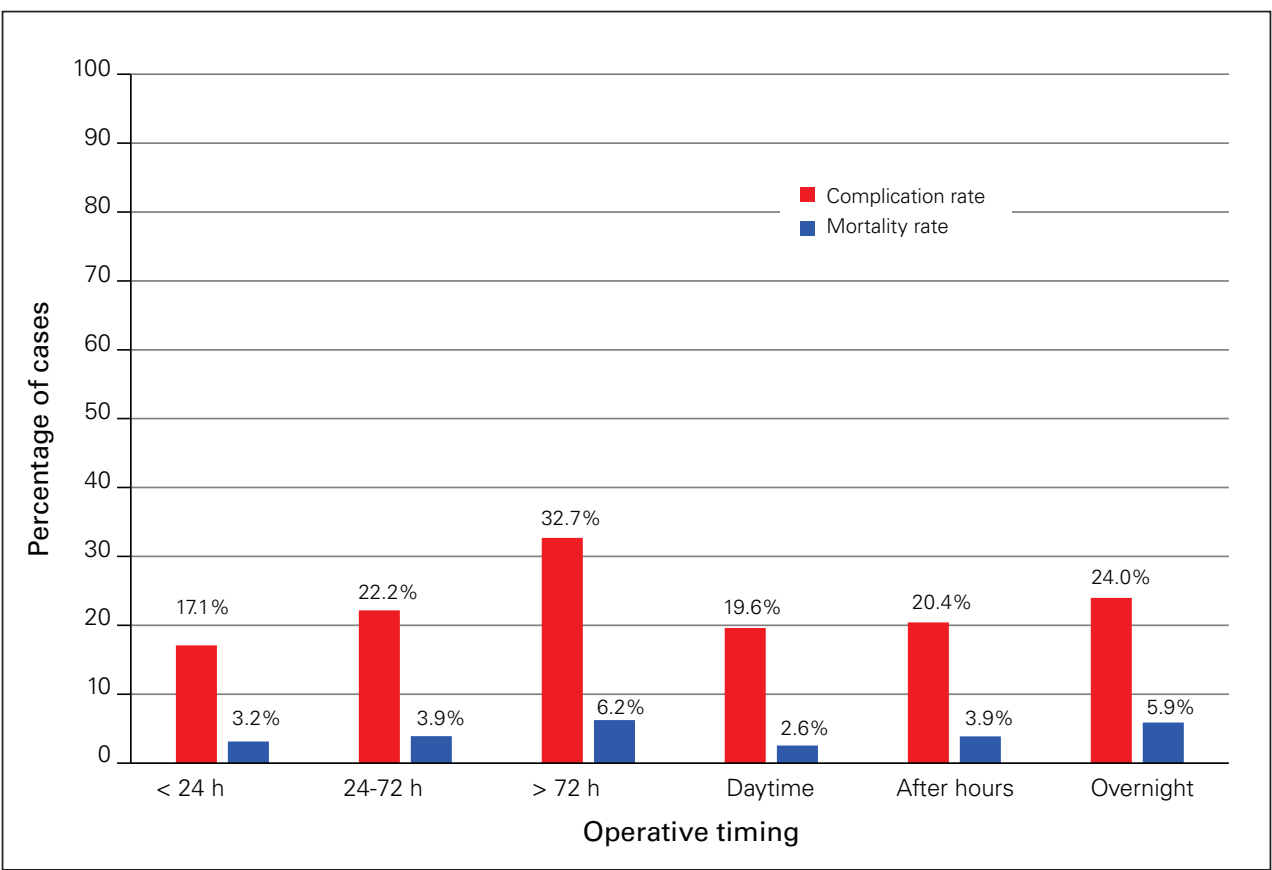

Fig. 3. Complication and mortality rates by time to operation ( $<24 \mathrm{~h}, 24-72 \mathrm{~h},>72 \mathrm{~h})$ and by time of operation (daytime, after hours, overnight). hospital stay. ${ }^{1-3}$ Hospitals hope to be able to streamline services, improve bed flow and improve cost efficiency. ${ }^{4-6}$ Surgeons look to the many potential benefits of ACS services, such as reduced disruption to elective practice, increased job satisfaction and perhaps even the prospect of equalization of disparities among surgeons. ${ }^{7,19}$ Even learners stand to benefit, given the potential for high-intensity exposure to a large volume of critically ill patients requiring operative and nonoperative management.

Although many of these improvements are worth pursuing in their own right, the core of the ACS concept has always been service to the EGS patient. A recent metaanalysis confirmed that, for biliary and appendiceal disease, this model reduces complications and length of admission..$^{20}$ Unfortunately, these improvements disappear without daytime access to the operating room.

Timeliness of care is paramount for the emergency surgical patient. In our patient population, operations occurring more than 72 hours after admission were associated with an increased risk of complications, irrespective of disease process. Likewise, overnight operations were associated with a 3 times higher odds of death than daytime operations. Similar results have been previously published. In a detailed analysis, McIsaac and colleagues effectively found that delay to the OR was associated with increased hospital costs, length of stay and in-hospital mortality. ${ }^{24}$ Although their study accounted for a broad range of emergency surgical conditions, from orthopedic to urologic, we were able to demonstrate that this finding holds true for the specific subset of diseases that general surgeons encounter.

Table 4. Complications and mortality in cholecystitis and appendicitis

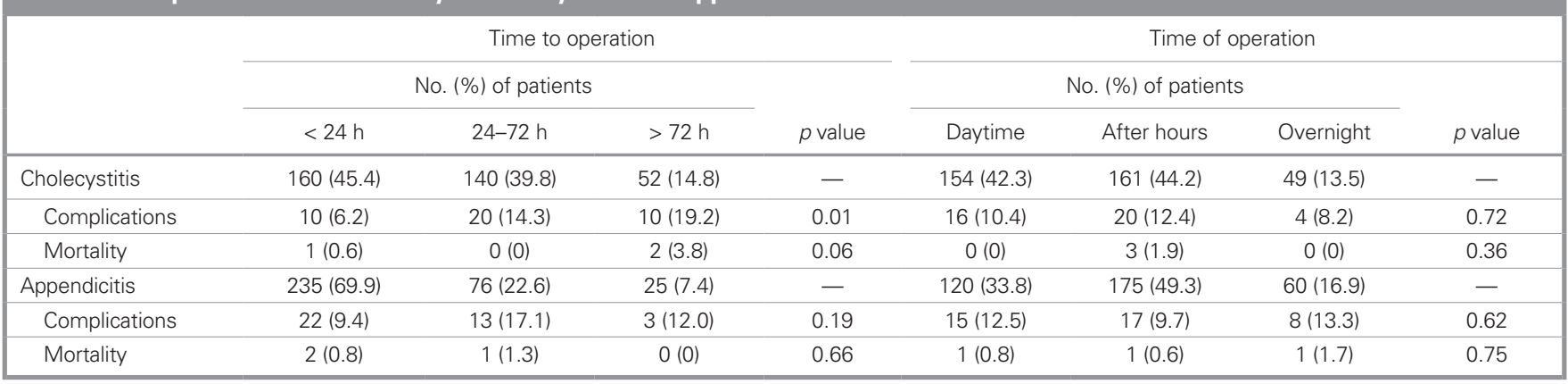


In spite of the risks associated with increased time to the operating room, a substantial proportion of cases in our study occurred during higher risk time frames. Our centre is not alone; a prior study on ACS services across Canada established that competition for access to the operating room is a common problem. ${ }^{8}$ Monitoring is also a challenge. As outlined by a recent systematic review on the impact of the ACS model on timeliness of care and patient outcomes, a lack of standard metrics and the absence of a dedicated comprehensive EGS database limit the ability to monitor performance and identify areas for quality improvement. ${ }^{21}$

Although the ACS model has been a beacon of hope for addressing these issues, attention must be paid to timely access to the operating room. Other groups have found that even after-hours operating confers increased risk to patients undergoing general and vascular surgery. ${ }^{22,23}$ Improved daytime operating room resources would be a potential solution to both time and timeliness, and if dovetailed with the ACS model it could be advantageous for patients, providers and trainees alike.

Strengths of the present study include the diverse set of EGS delivery models, including 1 non-ACS hospital. The EGS literature is heterogenous, typically examining either emergency surgery as a whole (general, trauma, orthopedics, cardiothoracic) $^{22-24}$ or a single EGS pathology (perforated peptic ulcer, appendectomy, diverticulitis), ${ }^{25-31}$ making it difficult to draw clear conclusions on the effect of time to operation. We were able to capture the disease processes for which the patients required surgery with improved precision and to account for this in our regression models. These factors may improve the generalizability of our results to other patients who may be encountered by the general surgeon on call, allowing for better care and empowered advocacy.

\section{Limitations}

A number of important limitations must also be acknowledged. Similar to other studies, our time to operation calculation was made using the time of admission, with the assumption that this is when the decision to operate was made. We attempted to account for this using sensitivity analyses, but these are no substitute for documented decisions. Importantly, data on patient comorbidities and physiologic status were unavailable for analysis, and these play an important role in determining timing of surgery and postoperative outcomes in this patient population. Future studies should endeavour to account for all possible relevant inputs, keeping in mind that this will require even larger high-quality data sets to avoid overfitting in multivariable analysis. Finally, time elapsed before operation could be increased for a myriad reasons, often by medical necessity, and it is difficult to know on a patient level why this is the case. Regardless, clinicians ought to be attentive to this matter, and while tending to their patients' immediate needs they should advocate for timely surgery.

\section{Conclusion}

Within our academic network comprising 3 EGS services of various service-model types, increasing length of time between admission and operation and overnight operating were associated with greater morbidity and mortality for EGS patients. Although multiple factors are probably at play, a lack of access to daytime operating room resources across our institutions is a modifiable system-based factor contributing to these findings. Moving forward, optimization of care for EGS patients in an ACS model should consider strategies to provide timely access to the operating room.

Affiliations: From the Department of Surgery, McMaster University, Hamilton, Ont. (Meschino, Giles, Rice, Saddik, Doumouras, Nenshi, Engels); and the Department of Surgery, Western University, London, Ont. (Allen, Vogt).

Competing interests: T. Rice has received speaker fees from Cook Medical. No other competing interests were declared.

Contributors: M. Meschino, A. Giles, M. Saddik, R. Nenshi, K. Vogt and $\mathrm{P}$. Engels designed the study. M. Meschino acquired the data, which M. Meschino, A. Giles, T. Rice, A. Doumouras, R. Nenshi, L. Allen, K. Vogt and P. Engels analyzed. M. Meschino, A. Giles and P. Engels wrote the article, which all authors critically reviewed. All authors approved the final version of the article to be published.

\section{References}

1. Earley AS, Pryor JP, Kim PK, et al. An acute care surgery model improves outcomes in patients with appendicitis. Ann Surg 2006;244:498-504.

2. Schaetzel S, Dirks R, Davis J. Comparison of outcomes of patients with acute appendicitis between an acute care surgery model and traditional call coverage model in the same community. Am 7 Surg 2016;212:1083-9.

3. Britt RC, Bouchard C, Weireter LJ, et al. Impact of acute care surgery on biliary disease. 7 Am Coll Surg 2010;210:595-9, 599-601.

4. Faryniuk AM, Hochman DJ. Effect of an acute care surgical service on the timeliness of care. Can 7 Surg 2013;56:187-91.

5. Cubas RF, Gómez NR, Rodriguez S, et al. Outcomes in the management of appendicitis and cholecystitis in the setting of a new acute care surgery service model: impact on timing and cost. $7 \mathrm{Am}$ Coll Surg 2012;215:715-21.

6. Murphy PB, Paskar D, Parry NG, et al. Implementation of an acute care surgery service facilitates modern clinical practice guidelines for gallstone pancreatitis. 7 Am Coll Surg 2015;221:975-81.

7. Austin MT, Diaz JJ Jr, Feurer ID, et al. Creating an emergency general surgery service enhances the productivity of trauma surgeons, general surgeons and the hospital. F Trauma 2005;58:906-10.

8. Vogt K, Allen L, Murphy P, et al. Patterns of complex general surgery emergencies in Canada [abstract]. Can 7 Surg 2018;61(4 Suppl 2):S104-5.

9. Ricci WM, Gallagher B, Brandt A, et al. Is after-hours orthopaedic surgery associated with adverse outcomes?: A prospective comparative study. 7 Bone foint Surg Am 2009;91:2067-72.

10. Chacko AT, Ramirez MA, Ramappa AJ, et al. Does late night hip surgery affect outcome? 7 Trauma 2011;71:447-53.

11. Moja L, Piatti A, Pecoraro V, et al. Timing matters in hip fracture surgery: patients operated within 48 hours have better outcomes. A meta-analysis and meta-regression of over 190,000 patients. PLoS One 2012; 7:e46175.

12. Simunovic N, Devereaux PJ, Sprague S, et al. Effect of early surgery after hip fracture on mortality and complications: systematic review and meta-analysis. CMAF 2010;182:1609-16. 
13. Worni M, Ostbye T, Gandhi M, et al. Laparoscopic appendectomy outcomes on the weekend and during the week are no different: a national study of 151,774 patients. World 7 Surg 2012;36:1527-33.

14. Ferguson HJ, Hall NJ, Bhangu A, et al. A multicentre cohort study assessing day of week effect and outcome from emergency appendicectomy. BM7 Qual Saf 2014;23:732-40.

15. Siada SS, Schaetzel SS, Chen AK, et al. Day versus night laparoscopic cholecystectomy for acute cholecystitis: a comparison of outcomes and cost. Am 7 Surg 2017;214:1024-7.

16. Wu JX, Nguyen AT, De Virgilio C, et al. Can it wait until morning? A comparison of nighttime versus daytime cholecystectomy for acute cholecystitis. Am 7 Surg 2014;208:911-8.

17. Phatak UR, Chan WM, Lew DF, et al. Is nighttime the right time? Risk of complications after laparoscopic cholecystectomy at night. 7 Am Coll Surg 2014;219:718-24.

18. Koltka AK, Ilhan M, Ali A, et al. Is nighttime laparoscopic general surgery under general anesthesia safe? Ulus Travma Acil Cerrabi Derg 2018;24:20-4.

19. Dossa F, Simpson AN, Sutradhar R, et al. Sex-based disparities in the hourly earnings of surgeons in the fee-for-service system in Ontario, Canada. FAMA Surg 2019;154:1134-42.

20. Murphy PB, DeGirolamo K, Van Zyl TJ, et al. Impact of the acute care surgery model on disease- and patient-specific outcomes in appendicitis and biliary disease: a meta-analysis. $7 \mathrm{Am}$ Coll Surg 2017;225:763-777.e13.

21. Vergis A, Metcalfe J, Stogryn SE, et al. Impact of acute care surgery on timeliness of care and patient outcomes: a systematic review of the literature. Can 7 Surg 2019;62:281-8.

22. Kelz RR, Freeman KM, Hosokawa PW, et al. Time of day is associated with postoperative morbidity: an analysis of the National Surgical
Quality Improvement Program data. Ann Surg 2008;247:544-52.

23. Kelz RR, Tran TT, Hosokawa P, et al. Time-of-day effects on surgical outcomes in the private sector: a retrospective cohort study. $7 \mathrm{Am}$ Coll Surg 2009;209:434-445.e2.

24. McIsaac DI, Abdulla K, Yang H, et al. Association of delay of urgent or emergency surgery with mortality and use of health care resources: a propensity score-matched observational cohort study. CMA7 2017;189:E905-12.

25. Vester-Andersen M, Lundstrøm LH, Buck DL, et al. Association between surgical delay and survival in high-risk emergency abdominal surgery. a population-based Danish cohort study. Scand 7 Gastroenterol 2016;51:121-8.

26. Ong M, Guang TY, Yang TK. Impact of surgical delay on outcomes in elderly patients undergoing emergency surgery: a single center experience. World 7 Gastrointest Surg 2015;7:208-13.

27. Buck DL, Vester-Andersen M, Moller MH. Surgical delay is a critical determinant of survival in perforated peptic ulcer. $\mathrm{Br}$ f Surg 2013;100:1045-9.

28. Azuhata T, Kinoshita K, Kawano D, et al. Time from admission to initiation of surgery for source control is a critical determinant of survival in patients with gastrointestinal perforation with associated septic shock. Crit Care 2014;18:R87.

29. Ingraham AM, Cohen ME, Bilimoria KY, et al. Effect of delay to operation on outcomes in adults with acute appendicitis. Arch Surg 2010;145:886-92.

30. Sicard N, Tousignant P, Pineault R, et al. Non-patient factors related to rates of ruptured appendicitis. Br 7 Surg 2007;94:214-21.

31. Mozer AB, Spaniolas K, Sippey ME, et al. Post-operative morbidity, but not mortality, is worsened by operative delay in septic diverticulitis. Int 7 Colorectal Dis 2017;32:193-9. 